\title{
DESCUBRIR LA \\ LITERATURA INFANTIL
}

\author{
DISCOVERING CHILDREN'S LITERATURE
}

\section{XIMENA TRONCOSO ARAOS*}

\section{RESUMEN}

¿Qué podemos hacer para formar el gusto por la lectura literaria en niños y niñas? Esta pregunta no solo apela a profesores, sino también a las madres, padres y a todo aquel que, de una u otra forma, tenga contacto cercano con niñas y niños y quiera contribuir a su formación como lectores y como personas. En relación con esto, planteo la importancia de descubrir o redescubrir la literatura infantil como lectores adultos. A partir de los aportes de estudios emparentados con el psicoanálisis, analizo principalmente por qué es en la literatura infantil donde encontramos los mayores clásicos de la literatura, y propongo la lectura de obras de calidad literaria, centrándome especialmente en obras que potencien el diálogo con y entre lectores infantiles y lectores adultos, obras que permitan el encuentro entre ambos sujetos.

Palabras clave: Literatura infantil, fomento lector, Gabriela Mistral, Marcela Paz, Hans Christian Andersen.

\section{ABSTRACT}

What can we do to for children to develop a taste for literary reading? This question not only appeals to teachers of the school system and initial teacher training, but also parents, and all those who, one way or another, have close contact with children and want to contribute to their development as readers and people. In this respect, I state the need to discover or rediscover children's literature as adult readers. From the contri-

* Dra. en Literatura Latinoamericana. Académica de la Facultad de Educación de la Universidad Católica del Maule.Curicó, Chile. Correo electrónico: xitrona@yahoo.com,xtroncos@ucm.cl 
butions of studies related to psychoanalysis, I mainly analyze why the greatest literature classics relate to children's literature. I suggest reading quality works, particularly those that enhance the dialogue with and between child readers and adult readers, and which allow these two types of readers to converge.

Keywords: Children's literature, reading promotion, Gabriela Mistral, Marcela Paz, Hans Christian Andersen.

Recibido: 08.03.12. Aceptado: 13.10.16.

$\mathrm{P}$ ARADÓJICAMENTE, a menudo escuchamos que la lectura está en crisis, que en general las personas leen muy poco y que los niños no quieren leer, aunque hoy en día se publican más libros que antes y son más las personas que acceden a la educación y que saben leer. No deja de llamar la atención que se reconozcan los beneficios de la lectura a la vez que se diagnostique escaso interés por esta actividad, especialmente por la lectura de libros. Esta problemática es compleja, multifactorial, y trasciende el acotado marco del aula, al que algunos pretenden circunscribirla. El escritor argentino Luis Pescetti señala que el discurso que promueve la bondad de la lectura choca con la realidad de sociedades que exaltan lo material, el éxito fácil y rápido: "La pérdida del gusto por la lectura no es ajena a los valores que se fueron escogiendo. A una sociedad que se fascina ante el éxito sin preguntarse por su contenido ni por cómo se obtuvo. Éxito, fama, punto. ¿Qué importa cómo?” (2014, párr. 4).

No obstante lo anterior, es necesario matizar y relativizar diagnósticos tan categóricos como "los niños no leen", "a los niños no les gusta leer" o "no saben leer". Tal vez, en lugar de que se insista en lo importante y lo bueno que es leer, sin mayor fundamento y con los argumentos tautológicos de que leer es importante para mejorar la comprensión lectora o para valorar la literatura, sería más productivo experimentar la lectura, es decir, leer, acercar los libros a los niños, a los jóvenes, a las personas, y conversar sobre y a partir de los libros, como propone Aidan Chambers (2007) con su enfoque didáctico Dime. Los niños no van a querer leer porque un adulto les diga que leer es bueno; es más, esto sería un motivo de sospecha o de rechazo, como la sopa para Mafalda. El escritor Daniel Pennac (2001) plantea que el propósito de acercar los libros y la lectura a los niños no es que todos sean lectores, sino que puedan elegir serlo. La lectura como dogma no ha dado ni está dando buenos frutos. En el ensayo Como una novela de Pennac un padre ficticio se pregunta en qué momento su hijo adolescente perdió el entusiasmo hacia los libros y, luego de escarbar en sus recuerdos, entiende 
que su relación como mediador entre los libros y su hijo cambió: de ser su narrador de historias se convirtió en su fiscalizador de lecturas.

En una de las buenas comedias de Hollywood, Cuando Harry conoció a Sally, Harry se jacta de saber siempre si una mujer tiene o no un orgasmo. La protagonista, Sally, para burlarse de su jactancia, finge un orgasmo en pleno restaurante. Una mujer que la observa pide a la camarera: “-Deme lo mismo que a ella”. Quiero usar esta escena como una alegoría, no del placer de la lectura, sino del deseo del placer del otro. Ciertamente que el placer lector es menos sencillo de falsear, por lo que el gusto auténtico por la lectura se vuelve indispensable.

El circuito de producción y recepción del libro infantil tiene características específicas y complejas: los actores de la comunicación corresponden a diferentes ámbitos: autores, intermediarios o mediadores (instituciones, editores, escuela), críticos y lectores (Lluch, 2004). Como señala Luch, el lector viene a ser doble: el adulto y el niño. El adulto, que puede ser alguien de la familia o un mediador, es quien compra, recomienda o establece las lecturas, especialmente para los lectores de edades más tempranas. Esa mediación de la lectura, presente e importante en la lectura infantil, implica un acto de comunicación sobre el que se vuelve necesario reflexionar, ya se trate de la "lectura en solitario" o "con los demás", como distingue Teresa Colomer (2005).

No obstante, actualmente los niños están ejerciendo cada vez más su derecho a elegir lo que leen y a opinar sobre los libros, ya que existe mayor definición de un campo de literatura para niños, con escritores que asumen a su destinatario. Por ende, los niños también se asumen como receptores de esos textos. Encontramos cada vez más libros cuyos paratextos apelan directamente a los niños y no a los mediadores. Los niños están siendo más escuchados en cuanto a sus gustos, lo que se evidencia en los índices de venta de las obras de algunos autores, que a menudo superan las ventas de escritores para adultos cuya producción es éxito de ventas.

Sin embargo, esto no significa que los adultos nos desliguemos de nuestro papel en la formación lectora. Al contrario, la vasta producción de literatura infantil de las últimas décadas vuelve más acuciante esta tarea, la que para el profesorado resulta aún más perentoria. Hoy en día asistimos a un incremento importante en la publicación de literatura infantil y juvenil, lo que en principio me hace pensar: ¡qué bien!, existe mayor interés por incluir a los niños como lectores, existe mayor interés por el mundo infantil por parte de quienes escriben y editan. Pero luego de incursionar en esta literatura, el alborozo cede paso a una mirada inquisitiva y a la decepción 
en muchos casos, pues no todo lo que brilla es oro. Es esto lo que a algunos escritores y críticos, como a Harold Bloom (2003), hacen cuestionar el uso del concepto literatura infantil o postular una "literatura sin adjetivos" (Andruetto, 2013).

A diferencia de lo que pudiera pensarse, no es fácil escribir literatura infantil de calidad, así como no lo es escribir literatura o, de manera más general, crear una obra artística. Esto es así si no renunciamos a la dimensión estética de la literatura infantil como condición inexcusable.

En este entendido, como mediadores, ¿qué textos podemos elegir para que los niños lean o para leer con ellos y para ellos? La respuesta que quiero dar no consiste en un listado de libros o un listado de temáticas. Mi respuesta es general y fundamental, y dice relación con la calidad de las obras. En ocasiones encontramos el criterio de calidad literaria como un aspecto importante a considerar al elegir textos para la infancia, sin embargo, no se precisa lo que se entiende por obra de calidad. A continuación, refiero algunos criterios a considerar (Troncoso, 2015, pp. xxxii-xxxvii). Pero es necesario advertir que estos criterios poco sirven si no leemos, pues es la práctica de la lectura la que nos permitirá entender tales aspectos y comparar obras.

\section{POLISEMIA O PLURISIGNIFICATIVIDAD}

La literatura, a diferencia de los textos funcionales pragmáticos, se abre a los sentidos, busca la polisemia, no la univocidad. Un aspecto que ha sido señalado por escritores y estudiosos de la literatura en general y de la literatura infantil en particular es la capacidad generadora de sentidos que esta posee. Una obra en tanto más polisémica, mayor es su potencial interpretativo, reflexivo y creador.

\section{TRABAJO CON EL LENGUAJE}

La polisemia se relaciona estrechamente con la forma como se cuenta la historia en el relato, con el lenguaje. Los textos literarios para niños también han de tener su espesor artístico en la escritura, con gestión de los recursos lingüísticos y los significados que pueden vehicular. Por tanto, es clave el trabajo con el lenguaje en su precisión, poder evocador, ludismo, configuración de los personajes, tejido narrativo, efecto de verosimilitud de 
acuerdo al verosímil y al género, relaciones intertextuales y paratextuales, entre otros aspectos.

\section{HUMOR}

Aunque no es un rasgo sine qua non, la importancia del humor ha sido señalada por escritores de literatura infantil y algunos estudiosos. Como lo afirma Soriano (1995, pp. 358-370), desde sus primeras manifestaciones, la literatura infantil se ha esforzado por utilizar la comicidad: a veces como un respiro, como un alto en el relato, y otras veces como procedimiento sistemático de creación, con el propósito de distender o de corregir. Sin embargo, mucha literatura infantil se caracterizó por su falta de humor. El humor en la literatura resulta atractivo para los niños y adultos, y puede tener un carácter lúdico o crítico.

\section{COMPROMISO ESTÉTICO Y ÉTICO}

La primera forma en que un escritor o una escritora evidencian su valoración de la infancia es escribiendo bien y con honestidad, sin las coacciones del mercado y sin subestimar a los niños. A la hora de tratar temas con implicancias políticas y sociales, es relevante que las obras se atrevan a tratarlos con una mirada crítica, cuestionando el mundo adulto y su autoridad, por la indiferencia, la violencia, la guerra, la discriminación en sus distintas formas, los regímenes dictatoriales, etc., y que, en contraste, promuevan implícitamente una sociedad que piense realmente en la infancia.

\section{POTENCIALIDAD PARA GENERAR DIÁLOGO ENTRE LECTORES NIÑOS Y LECTORES ADULTOS}

La literatura infantil de calidad proporciona un espacio de encuentro entre el sujeto infantil y el sujeto adulto, un reencuentro con la niña o niño que fuimos; por ende, permite un mayor acercamiento a los niños que nos rodean. Esto no lo logra cualquier texto clasificado bajo el rótulo de literatura infantil y juvenil, sino las obras que consiguen generar experiencia lectora en niños y adultos. Para ello, la honestidad del escritor o escritora en el momento de crear incidirá en la autenticidad que imprima a sus obras, 
cualquiera sea el tema y el tratamiento que decida adoptar, ya sea humorístico o serio. La niñez nunca nos deja, aun cuando hayamos olvidado mucho de ella.

De estos criterios de calidad señalados, me interesa centrarme aquí en el último. Este aspecto no ha sido considerado mayormente por los estudios en literatura infantil ni por la didáctica de la literatura, y resulta especialmente importante cuando se piensa en la lectura literaria infantil como actividad en que intervienen mediadores. Marc Soriano (1995) piensa que es importante atender al "diálogo que, de una época a otra, de una sociedad a otra, se entabla entre los niños y los adultos por intermedio de la literatura" (p. 213). Es interesante preguntarse qué formas de diálogo suscitan las obras entre los personajes infantiles y los personajes o figuras de adultos, y entre el niño histórico y los lectores adultos contemporáneos.

Propongo compartir con los niños la lectura de obras con los que hayamos establecido una relación cercana, obras que nos apelen hoy en día como adultos que somos y como niñas y niños que fuimos, que disfrutemos al leerlos en voz alta, que al comentarlos transmitamos nuestro placer. Es cierto que el placer lector es una experiencia personalísima que no podemos traspasar al otro. Por tanto, mi placer no garantiza el del otro, pero sí es un germen que amplifica las posibilidades de contagiar el interés por una obra y despertar el interés por otras. Ahora bien, cuando hablamos del placer lector, hemos de entender algo más complejo y sutil que una mera entretención, risa o alegría. Tal idea es la que ha hecho cuestionar a algunos el énfasis que algunos enfoques han puesto en el placer de la lectura. Gustavo Bombini (2005) se ha referido críticamente a tales enfoques como "pedagogía del placer". Creo que el placer del que hablaba Roland Barthes (1987) no era esta superficialidad que encontramos a menudo y que en ocasiones poco tiene que ver con la lectura. Barthes visualizaba el acto de lectura en solitario levantando la cabeza, porque algo nos mueve por momentos, nos apela, nos remece, nos duele, nos hace pensar.

¿Cuándo o de qué manera se logra escribir literatura infantil de calidad? En principio, cuando se escribe con libertad, es decir, cuando se escribe por oficio literario, sin coacciones internas o externas, cuando no se subestima al lector y cuando se renuncia a escribir bajo el mandato de educarlo, en el sentido de proyectar una intención didáctica, funcional, que determina las características de la obra y que se impone a la función estética de la literatura. Si bien se ha avanzado en el ámbito literario y educacional con respecto a la visión de la literatura para la infancia, la función educativa, especialmente valórica, con un tratamiento reduccionista de las obras, aún 
tiene fuerte presencia a la hora de producir y seleccionar obras para niños (Carranza 2006; Colomer, 2005; Munita, 2010; Cerrillo, 2015), y muchas veces se impone en los catálogos de libros y en la práctica docente. La literatura se instrumentaliza para que sea útil, y se la percibe útil en la medida que sirve para trabajar algún contenido lingüístico, como aprender vocabulario, o algún objetivo o tema transversal. Pero sabemos que estos aspectos en sí mismos no garantizan la calidad literaria de las obras. Estas concepciones parecen relacionarse con el perfil lector del docente. Munita (2013) muestra que la visión sobre la literatura y la educación literaria presenta diferencias importantes entre los futuros profesores que son lectores fuertes y los lectores débiles, lo que da razón a la idea de que los lectores forman lectores.

Para generar un ambiente de lectura interesante, en conexión con las obras, propongo buscar la convergencia entre los intereses de los niños y los nuestros. La invitación es a construir nuestro propio corpus. La crítica literaria puede aportar, sin duda, a esta construcción, aunque, en definitiva, la selección ha de ser siempre personal. En este trabajo intento señalar algunos caminos, iluminar algunas zonas, desestabilizar otras. Especialmente, me interesa abrir la reflexión de la literatura infantil enfatizando su estatus literario y atendiendo a la riqueza de significados en relación con las experiencias humanas y la subjetividad de los lectores.

Las obras clásicas de la literatura infantil se caracterizan por trascender lo etáreo. En ciertos casos, se trata de textos que no fueron concebidos de manera intencionada para destinatarios, oyentes o lectores, infantiles, pero cuya escritura logra incluirlos. En otros casos, las obras pensadas para niños involucran a los lectores adultos porque configuran experiencias humanas diversas y profundas, en una composición virtualmente cautivante. Una literatura infantil que logre esto, seguramente trascenderá el paso de generaciones. Pedro Cerrillo alude a esta conexión entre el mundo del niño y el del adulto en la literatura infantil: "El mundo de la LIJ es, al menos en parte, una consecuencia de la fascinación que el niño ejerce sobre el adulto (...) durante cientos y cientos de años, los adultos han contado a los niños relatos que expresan los conflictos del alma infantil, sin eludir la maldad, la fealdad o el miedo, porque también forman parte de su mundo" (2015, p. 15).

En este sentido, desde el psicoanálisis se han realizado grandes aportes al estudio y valoración de la literatura infantil. Bruno Bettelheim, con Psicoanálisis de los cuentos de hadas (2006 [1975]), y Clarisa Pinkola Estés, con Mujeres que corren con lobos (2004 [1992]), han contribuido de manera 


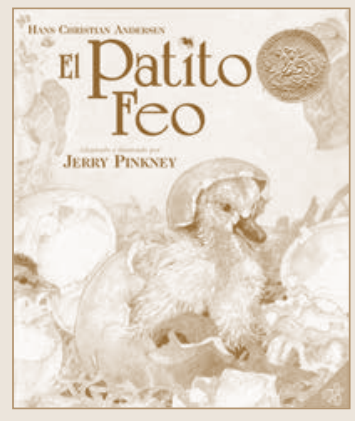

fundamental a una mayor comprensión de esta literatura, si lo miramos desde una perspectiva hermenéutica, y también han generado nuevas formas de relación con esta literatura, si nos planteamos desde una perspectiva de la filosofía del deseo. Estos autores, no obstante escribir desde ámbitos diferentes al literario, elaboran interpretaciones que no abandonan las consideraciones artísticas relativas a los textos, sino al contrario. Lo que me interesa destacar en Bettelheim es que nos muestra la potencialidad y complejidad de significados de los textos al construir un universo de significación que las obras hacen posible. El acento de Bettelheim está en el análisis de los cuentos en relación con el conocimiento del universo psíquico infantil. Pinkola Estés, por su parte, demuestra la validez de la literatura infantil tradicional para los lectores adultos, especialmente para la salud psíquica de las mujeres. Es interesante cómo Pinkola Estés, desde una perspectiva de género, muestra cómo es posible leer significados que superan otras lecturas de género que reprueban apresuradamente los cuentos infantiles tradicionales.

¿Qué hace posible la coexistencia de dos lecturas diferentes como las de Bettelheim y Pinkola Estés? Mi respuesta es que aquello que lo hace posible es el carácter minoritario del sujeto infantil y del sujeto femenino en la historia cultural. La identificación con los relatos se cumple en sujetos diferentes, niños y adultos, hombres o mujeres. La configuración de experiencias nos apela como resonancia de un pasado infantil en sus aspectos idílicos e inquietantes, o como recurrencias de conflictos humanos que los textos ficcionalizan. Sin embargo, no defiendo los significados particulares que proponen estas lecturas, sino el acercarnos a una comprensión de la trascendencia de una literatura infantil. ¿Por qué el psicoanálisis logra esto? La respuesta estaría, en principio, en el hecho de que el psicoanálisis conecta al adulto con la infancia.

"El patito feo", cuento de Hans Christian Andersen, puede inspirar lecturas asociadas a diferentes experiencias, tanto de la infancia como de la adolescencia y de la edad adulta. La lectura de Pinkola Estés del cuento de Andersen, si bien aplicada a la experiencia femenina, deja ver su relación con otras formas de experiencia, en que se busca un lugar en el mundo donde encontrar un ambiente propicio para el desarrollo personal en sintonía con otros.

Si relacionamos las lecturas y propuestas de ambos autores, podemos percatarnos de su complementariedad y, en consecuencia, de que la literatura infantil -cierta literatura infantil, la que nos interesa-, no es excluyente sino inclusiva. La literatura proporciona un espacio de encuentro entre el 
sujeto infantil y el sujeto adulto, un reencuentro con la niña o niño que fuimos; por ende, permite un mayor acercamiento a los niños que nos rodean. Quiero enfatizar que esto no lo logra cualquier texto clasificado bajo el rótulo de literatura infantil y juvenil, sino las obras que consiguen generar un diálogo con lectores infantiles y adultos. La niñez nunca nos deja, aun cuando hayamos olvidado en el consciente mucho de ella. Una obra infantil de calidad puede y merece ser leída a cualquier edad, aunque los significados y sentidos varían entre adultos y niños. Así, en el caso de los cuentos de hadas, por supuesto que los niños no elaborarán un análisis sicoanalítico, sino que sus lecturas entrañan un aprendizaje síquico que los conecta con sus experiencias y su mundo afectivo. Al decir, de Bettelheim, dan sentido a su mundo.

Así, me parece que los clásicos infantiles son las obras más universales que existen; son los textos verdaderamente universales, pues logran incluir al sujeto infantil lector y también al adulto. Sin embargo, la literatura infantil ha sido injustamente minorizada. La calidad literaria es diversa en todo orden literario, por lo que la marginación de la literatura infantil no obedece tanto a la calidad como a la concepción de la niñez y al lugar que se le ha asignado en las sociedades.

Este encuentro o relación entre el sujeto infantil y el adulto es una de las experiencias síquicas sensibles, como nos lo ha mostrado el sicoanálisis, la literatura y otras formas artísticas. Gabriela Mistral tuvo plena conciencia de que la experiencia de la infancia es trascendental y que nos acompaña siempre, de ahí que encontremos textos relativos a la infancia en varios de sus libros. Su lírica y relatos infantiles también son testimonio de su visión de la infancia, los que aceptan diferentes niveles de significación, y no son solo de lectura para niños. Jaime Quezada (1989) advirtió que Ternura no es "libro menor o de intenciones meramente pueriles (...) está lejos de cumplir, a página cabal, con una 'empalagosa o catequística pedagogía'. Más bien se escribió originalmente como una reacción a la poesía escolar en boga en aquella época" (p. 109). Mistral, con mirada crítica sobre la poesía escolar, propuso y promovió una poesía que no abandonara el carácter literario, artístico: "que no por ser escolar deje de ser poesía, que lo sea, y más delicada que cualquiera otra, más honda, más impregnada de cosas de corazón: más estremecida de soplo de alma” (Mistral, 1945, citado en Quezada, 1989, p. XVII).

Pensemos en el poema "La pajita", sobre el cual Mistral expresó lo siguiente: "Les parecerá extraño, pero entre todos mis trabajos, el que prefiero es una pequeña canción de cuna que escribí con el título de 'La pajita'.

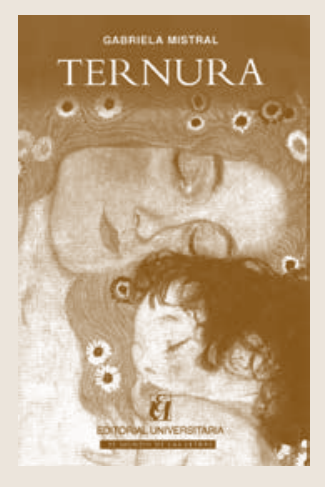


Debe ser porque yo siento un profundo afecto por esta clase de poesía" (en Quezada, p. XIX).

Esta que era una niña de cera; pero no era una niña de cera, era una gavilla parada en la era. Pero no era una gavilla sino la flor tiesa de la maravilla. Tampoco era la flor sino que era un rayito de sol pegado a la vidriera. No era un rayito de sol siquiera: una pajita dentro de mis ojitos era.

¡Alléguense a mirar cómo he perdido entera, en este lagrimón, mi fiesta verdadera! (Mistral, 2001, p. 258)

La poeta de Elqui manifiesta un profundo afecto por la tradición oral, de la que se nutre este tipo de poemas, que ella denomina "jugarretas" en su libro Ternura, y que la vinculan con la primera infancia. Manuel Peña Muñoz (1984) ha destacado la importancia de la tradición oral para la formación estética y ética de los niños. Peña señala que las nanas o canciones de cuna son "formas del folklore infantil" que constituyen "las primeras manifestaciones literarias y musicales que escucha el niño" (p. 9). La fórmula de inicio del poema, "Esta que era", nos envía al espacio-tiempo de los relatos orales de la tradición popular en Chile, en los que encontramos las formas "Esta era" o "Estera", como lo muestran las recopilaciones de Yolando Pino (1960), Oreste Plath (1962) y Manuel Peña (1984). Estas fórmulas son más comunes en la oralidad que "Había una vez", la que se identifica más con los cuentos de hadas clásicos.

Los textos para niños de Gabriela Mistral responden a íntimas necesi-

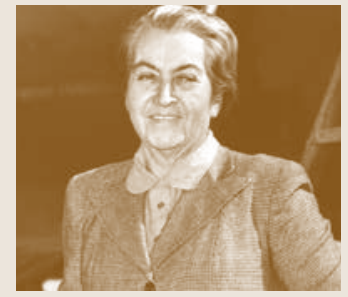

G. Mistral dades de expresión. En el caso de las canciones de cuna, el arrullo del sujeto poético no es solo el arrullo de un niño, sino el arrullo de sí misma, en un repliegue en que se vuelve al regazo protector de la madre. Sin embargo, el arrullo termina, así como la infancia; la fiesta de color y vida se esfuma tras el lagrimón. El intento imposible de aferrarse a la madre, presente en la poesía de Mistral (Marchant, 1984), tiene su manifestación tal vez más acendrada en esta clase de poemas y en este poema en particular. La jugarreta adquiere una doble connotación: el juego infantil en que las cosas se transforman con la imaginación, así como el cambio de nuestra persona, del mundo y de nuestra situación en él: el envés y el revés de las cosas y de la existencia. 
Quiero traer aquí un clásico de la literatura infantil chilena y, digámoslo, de la literatura chilena sin más, el cual también se ha dado a conocer en otros idiomas. Me refiero a Papelucho, de la escritora Marcela Paz, novela escrita en 1937 y publicada por primera vez en 1947. Papelucho corresponde a lo que creo es un verdadero clásico infantil. La obra conforma una serie de doce novelas cortas, cuando aún no se imponía esto como una moda. Papelucho se relaciona con la literatura infantil anterior, en parte cuestionándola y en parte retomándola. Es a través de este proceso de selección y composición que la autora crea una obra literaria con identidad propia, cuya mayor virtud es la configuración del personaje protagónico: su visión y su discurso íntimamente ligados.

El escritor Alberto Fuguet comparte su experiencia de lectura de $\mathrm{Pa}$ pelucho desde su vivencia personal como hijo de emigrantes radicados en EE.UU. que vuelven a Chile durante la dictadura, e intentan adaptarse a un nuevo espacio y a una "nueva" lengua. Según el escritor, la obra lo reconcilia con el español a través del discurso de su protagonista: "hablaba (en rigor, escribía) en un español real, de la calle, salpicado de escupo; de inmediato le creí todo lo que me confidenciaba" (2002, párr. 2). El escritor enfatiza el discurso del personaje como niño que escribe un diario de vida. Como bien lee Fuguet (2007), Papelucho es y no es una obra para niños, y el protagonista viene a constituirse en uno de los personajes fundamentales del canon literario nacional.

La obra logra modular un registro infantil y crear el efecto de la perspectiva infantil que no todo texto para niños consigue. En este sentido, fue un acierto de Marcela Paz optar por el diario de vida apócrifo, pues es el propio personaje, Papelucho, quien nos cuenta sus vivencias con un lenguaje infantil muy empático y con situaciones singulares que apelan a experiencias comunes, aunque con un sello particular. Algunas situaciones tienen un carácter local, con referencias geográficas, culturales e históricas; otras son de carácter más bien universal. El diario de vida da libertad a la autora para hacer hablar al personaje desde sus pensamientos y sentimientos íntimos, y nos permite acceder a un discurso sin la moral censuradora del adulto. Nos acerca a la construcción moral del niño, como se aprecia en esta cita de Papelucho: "A veces me dan ganas de quemar la casa, pero de antes ya me vienen los remordimientos y me echan todo a perder" (1997, p. 26). Marcela Paz consigue algo que no siempre está en las obras de literatura para niños, que es modular un discurso infantil realista a la vez que verosímil.

La obra se inscribe en el verosímil realista, en el género relato de aventuras cotidianas. No obstante, como muchos de los héroes de los cuentos ma- 
ravillosos tradicionales, el personaje vive en un espacio familiar conflictivo, del cual sale, vive aventuras y al cual regresa. En la serie Papelucho, el hogar es un pivote, un lugar al cual Papelucho siempre vuelve. El personaje no puede ni quiere desprenderse del núcleo familiar. Pero este no se muestra como un espacio idealizado, sino problemático. El texto se resiste a encasillar al personaje en el estereotipo del niño siempre feliz, ignorante de la desilusión y el sufrimiento. Esto contribuye también a que tanto los niños como los adultos lo perciban como verdadero, pues reconocemos en ello una experiencia humana común. Papelucho desmitifica el hogar y la familia, como espacio y entidad idealizados. En algunos momentos, Papelucho se va voluntariamente del hogar, con lo que la autora ficcionaliza un pensamiento y deseo común de la experiencia infantil: el de haber sido tratado injustamente, de modo que la fuga del hogar es vista como una forma de castigar a la familia para que lo valoren.

Pero, a pesar de que la historia representa aspectos poco amables de las relaciones familiares, Papelucho no resulta un libro de tono grave, pues el humor también está presente en buena dosis. Sobre el humor en Papelucho, Edgardo Cifuentes plantea que se trata de un "humor leve", que conjuga dos elementos: "una realidad 'criticable' (ya sea por sus defectos morales, ya por su severidad) y una perspectiva especial de la conciencia humorística que observa esa realidad" (2011, p. 30), lo que genera una distensión respecto a esa realidad, según el autor. Si bien el tono que impera es leve y no grave, creo, a diferencia de Cifuentes, que no es inofensivo. El humor y la risa no anulan la crítica social que opera por medio del discurso del personaje, por sus acciones y las relaciones de amistad con niños pobres. Por algo Papelucho fue una obra vista con sospecha al aparecer en el mercado editorial, por el niño cuestionador y no siempre bien portado que configuraba en sus páginas, así como porque visibiliza la gran desigualdad social.

El humor en la serie Papelucho funciona en distintos niveles, lo que favorece su universalidad etárea. El razonamiento infantil muchas veces nos despierta risa y ternura a la vez, al no estar ajustado a las normas sociales y al no regirse por un pensamiento logocéntrico sino mágico e ingenuo. Por ejemplo, en Papelucho, primer libro de la serie, el niño cree que su nana, la empleada de la casa y niñera, se ha comido un sándwich que él preparó para un ratón goloso, y que ella se va a morir producto de eso: "La Domitila todavía no se ha muerto. Yo hice una promesa para que no se muriera y prometí ser santo. Hoy regalé todas mis cosas, porque para ser santo es necesario regalarlo todo. Todo, menos mi pelota de fútbol, mi escopeta, $\mathrm{mi}$ revólver y otras cosas que necesito" (p. 12). 
El léxico también contribuye al humor, al atreverse la autora a incluir neologismos y distorsión de vocablos en su forma y significado como recursos de verosimilitud a la vez que de creatividad y humor: "la mamá se quedó estítica", en lugar de estática; "carné de castidad", en lugar de carné de identidad.

Las características del personaje, con sus matices y su voz propia, mantienen la obra como lectura actual, pues, en definitiva, logra que percibamos cierta verdad, la verdad subjetiva de la literatura: la paradoja literaria de la que hablaba Juan José Saer (1997): la ficción recurre a lo falso para aumentar su credibilidad. Esta actualidad de Papelucho hemos podido apreciarla en un proyecto de investigación en ejecución. Cito algunos comentarios de estudiantes de sexto año básico, pues ratifican lo que aquí planteo sobre $\mathrm{Pa}$ pelucho, y muestran cómo las obras de calidad pueden generar experiencias de lectura enriquecedoras:

Paz: cuando leo el libro, es como si lo hubieran hecho para nosotros, porque ella [Marcela Paz] quizás cuando lo escribía se daba cuenta de cómo hablaban los niños... de ahora. Entonces, como que ella, para que uno sintiera ganas de leerlo, le puso esas frases.

Martina: cuando lo voy leyendo siento risa, siento pena, me pongo a llorar, a veces me pongo seria.

Mariana: a mí me daba risa y a veces me sentía igual a él (...) Lo recomendaría, no por presumir, pero a todos, porque así verían que el racismo, algunos que son racistas, verían que uno no tiene que ser malo con las personas que son pobres, que son morenitas. ${ }^{1}$

Existen verdades comunes para niños y adultos en la literatura infantil, así como también existen modulaciones y niveles de significación para diferentes lectores en una obra infantil. Para generar sentidos, recomiendo empezar por zambullirse en los textos como lectores, como mujeres u hombres que somos, y como niñas y niños que fuimos, de modo de elegir esas

${ }^{1}$ Estas citas corresponden al registro de la entrevista grupal realizada a seis estudiantes del sexto básico de una escuela municipal de Curicó, en la que se realizó el estudio de campo del proyecto de investigación Recepción lectora de la obra Papelucho, de Marcela Paz, en estudiantes de educación básica, financiado por la Universidad Católica del Maule. La entrevista se efectuó después de cuatro sesiones de lectura y comentarios sobre y a partir de la obra Mi hermano hippie, por Papelucho, con 28 estudiantes. Investigadora responsable: Dra. Ximena Troncoso Araos. Coinvestigadora: Macarena Navarro. 
obras que nos motivan. Luego, transmitamos nuestro encanto compartiendo lo que las obras nos provocan y evocan, y reparemos en la forma en que lo consiguen, es decir, en el trabajo artístico de la escritura.

Finalmente, y a partir de esta reflexión, sugiero seleccionar como lectura no necesariamente todo lo que está canonizado como clásico de la literatura infantil o lo que las editoriales o los programas pedagógicos nos recomiendan que leamos, sino lo que hagamos nuestro en ese diálogo entre el niño y el adulto que algunos textos consiguen, esa clase de obras como para leer de niños y releer o descubrir de adultos.

\section{REFERENCIAS}

Andersen, H. Ch. (2004). "El patito feo". En Pinkola Estés, C., Mujeres que corren con lobos (Trad. María Antonia Menini). Buenos Aires: Ediciones B.

Andruetto, M. T. (2013). Hacia una literatura sin adjetivos (2a reimpr.). Buenos Aires: Comunicarte.

Barthes, R. (1987). El susurro del lenguaje. Más allá de la palabra y la escritura (Trad. C. Fernández Medrano). Madrid: Paidós.

Bettelheim, B. (2006 [1975]). Psicoanálisis de los cuentos de hadas (Trad. Silvia Furió). Barcelona: Editorial Crítica.

Bloom, H. (2003). "Introducción". Relatos y poemas para niños extremadamente inteligentes de todas las edades. Barcelona: Editorial Anagrama.

Bombini, G. (2005). La trama de los textos. Problemas de la enseñanza de la literatura. Buenos Aires: Lugar.

Carranza, M. (2006). "La literatura al servicio de los valores, o cómo conjurar el peligro de la literatura”. Imaginaria, 181. Recuperado de http://www.imaginaria.com.ar/ 18/1/ literatura- yvalores.

Cerrillo Torremocha, Pedro (2015). LIJ. Literatura mayor de edad. Cuenca: Ediciones de la Universidad de Castilla-La Mancha.

Cifuentes Becerra, E. (2011). "Marcas discursivas y narrativas del humor leve en Papelucho". Literatura y Lingüística, 24, 15-32.

Colomer, T. (2005). Andar entre libros. La lectura literaria en la escuela. México: Fondo de Cultura Económica.

Chambers, A. (2007). Dime. Los niños, la lectura y la conversación (Trad. Ana Tamarit). Amieva-México: FCE.

Fuguet, A. (2002, 19 de enero). "Rebelde con causa. Un chico subversivo". Revista de Libros de El Mercurio, 7.

. (2007, 22 de abril). "Papelucho revisitado". Alberto Fuguet: escritor/ lector. Blog del autor. Disponible en http://albertofuguet.blogspot.com /2007/04/papelucho-revisitado.htmlr

Lluch, G. (2004). Cómo analizamos relatos infantiles y juveniles. Bogotá: Editorial Norma. 
Marchant, Patricio (1984). Sobre árboles y madres. Santiago: Lead.

Mistral, G. (2001). “Ternura”. Poesías completas. Barcelona: Editorial Andrés Bello.

Munita, F. (2010). Literatura y escuela: un diálogo posible. Valdivia: Kultrún. . (2013). "Creencias y saberes de futuros maestros (lectores y no lectores) en torno a la educación literaria". Ocnos, 9, 69-87. Recuperado de http://www.revista.uclm. es/index.php/ocnos/article/view/227

Paz, M. (1997). Papelucho. Santiago: Editorial Universitaria.

Pennac, D. (2001). Como una novela ( $8^{\mathrm{a}}$ ed., Trad. Joaquín Jordá). Barcelona: Anagrama.

Peña Muñoz, M. (1984). Para saber y cantar: El libro del folklore infantil chileno. Santiago: Ediciones Cerro Huelén.

Pescetti, L. (2014). "No leerás". Luis Pescetti. Página web del autor. Disponible en http://www.luispescetti.com/no-leeras/

Pinkola Estés, C. (2004 [1992]). Mujeres que corren con lobos (Trad. María Antonia Menini). Barcelona: Ediciones B.

Pino Saavedra, Y. (1960). Cuentos folklóricos de Chile, t. 1. Santiago. Ediciones de la Universidad de Chile.

Plath, O. (1962). Folklore chileno. Santiago: Ediciones Platur.

Quezada, J. (1989). "Gabriela Mistral: algunas referencias a Ternura”. Acta Literaria, 14, 109-119.

Rainer, R. (director) (1989). Cuando Harry conoció a Sally. Título original When Harry met Sally [película]. Estados Unidos: Castle Rock Entertainment y Nelson Entertainment.

Saer, J. J. (1997). El concepto de ficción. Buenos Aires: Espasa-Calpe, Ariel.

Soriano, M. (1995). La literatura para niños y jóvenes. Guía de exploración de sus grandes temas (Trad.Graciela Montes). Buenos Aires: Colihue.

Troncoso Araos, X. (2015). “Criterios de selección”. En Troncoso, X. y Rubio, C. Antología crítica del relato infantil sudamericano. Concepción: Universidad de Concepción y Universidad Católica del Maule. 